\title{
Continuous jugular venous oximetry in the neurointensive care unit - a brief review
}

\author{
[L'oxymétrie continue de la veine jugulaire à l'unité des soins intensifs \\ neurologiques - une brève revue]
}

Hayden White FCP(SA), Andrew Baker MD FRCPC

Purpose: To describe the technique of continuous jugular venous oxygen saturation $\left(\mathrm{S} V \mathrm{O}_{2}\right)$ monitoring and review its applications in the neurointensive care unit (NICU), with special reference to the management of raised intracranial pressure (ICP) following severe acute brain injury.

Source: This narrative review is based on a selection of current literature on $\mathrm{SjVO}_{2}$ monitoring in conjunction with local experience using this technique.

Principal findings: Despite limitations, the use of $\mathrm{SjVO}_{2}$ monitoring has the potential to impact on patient care in the NICU. The placement of the catheter is relatively simple. Studies have confirmed that abnormalities in cerebral venous oxygen saturation are associated with adverse outcome following traumatic brain injury. There is evidence that $\mathrm{SjVO}_{2}$ may be a useful adjunct to ICP monitoring of patients with intracranial hypertension. Furthermore, managing cerebral extraction of oxygen in conjunction with cerebral perfusion pressure may result in an improved outcome. Further research in this area is needed. Other indications for $\mathrm{SjVO}_{2}$ monitoring include subarachnoid hemorrhage, cardiopulmonary bypass and following ischemic stroke.

Conclusion: In the past, the management of severe acute brain injury was targeted at ICP and perfusion pressure with little consideration for the metabolic requirements of the injured brain. $\mathrm{SjVO}_{2}$ monitoring is another tool the intensivist can use to obtain information about the global oxygen requirements of the injured brain on a continuous basis. Whether this will impact on care in the long term remains to be seen.

Objectif : Décrire le monitorage continu de la saturation en oxygène de la veine jugulaire $\left(\mathrm{SO}_{2} \mathrm{Vj}\right)$ et revoir son application à l'unité des soins intensifs neurologiques (USIN) en évoquant spécialement le traitement de l'hypertension intracrânienne (HTIC) faisant suite à une sévère lésion cérébrale aiguë.
Source : La revue narrative repose sur une sélection d'articles récents sur le monitorage de la $\mathrm{SO}_{2} \mathrm{Vj}$ en conjonction avec une expérience locale d'utilisation de cette technique.

Constatations principales : Malgré certaines limites, l'utilisation du monitorage de la $\mathrm{SO}_{2} \mathrm{Vj}$ peut influencer les soins données à l'USIN. La mise en place du cathéter est relativement simple. Des études confirment que des anomalies de la saturation en oxygène du sang veineux cérébral sont associées à des complications suivant une lésion cérébrale traumatique. II y a des indications à l'usage de la $\mathrm{SO}_{2} \mathrm{Vj}_{\mathrm{j}}$ comme auxiliaire utile au monitorage de la PIC des patients souffrant d'hypertension intracrânienne. De plus, le contrôle de l'extraction cérébrale d'oxygène en conjonction avec celui de la pression de perfusion cérébrale pourrait améliorer l'évolution. II faut toutefois poursuivre les recherches dans le domaine. D'autres indications pour le monitorage de la $\mathrm{SO}_{2} V_{j}$ comprennent l'hémorragie sous-arachnoïdienne, la circulation extracorporelle et les suites d'un accident ischémique cérébral.

Conclusion : Dans le passé, le traitement d'une sévère lésion cérébrale aiguë ciblait la PIC et la pression de perfusion et attachait peu d'importance aux besoins métaboliques du cerveau lésé. Le monitorage de la $\mathrm{SO}_{2} \mathrm{Vj}$ est un autre outil que les intensivistes peuvent utiliser pour obtenir, en continu, de l'information sur les besoins globaux en oxygène du cerveau lésé. II reste à déterminer si la technique influencera les soins à long terme.

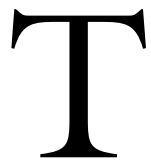

HE past decade has seen a resurgence of interest in neurocritical care. Until recently, management of severe acute brain injury has been directed almost solely at intracranial pressure (ICP) and cerebral perfusion pressure (CPP). With newer technologies, it is now possible to assess the injured brain from a metabolic perspective, and thus raise the prospect of making important inter-

From the Trauma and Neurosurgery Intensive Care Unit, Department of Anaesthesia, St Michael's Hospital, Toronto, Ontario, Canada. Address correspondence to: Dr. Andrew Baker, Department of Anaesthesia, St Michael's Hospital, 30 Bond Street, Toronto, Ontario

M5B 1W8, Canada. Phone: 416-864-5510; Fax: 416-864-5512; E-mail: bakera@smh.toronto.on.ca Accepted for publication December 7, 2001.

Revision accepted March 13, 2002. 
ventions. The brain is thought to depend entirely on oxygen to fulfill its energy needs and is the rationale for the observation that cerebral tissue is highly susceptible to oxygen deficits. In turn, oxygen delivery is dependent on cerebral blood flow (CBF), and although it is highly regulated in the healthy individual, injury often leads to a loss of blood flow regulation. It would therefore be useful to have a measure of the cerebral oxygen deficit. While several techniques are available, among the most extensively investigated is the measurement of jugular venous oxygen saturation $\left(\mathrm{SjVO}_{2}\right)$. The difference between the venous and arterial oxygen saturation is used to interpret the cerebral oxygen requirements and to guide therapy. Whether this leads to improved outcome is not known at present.

\section{Pathophysiology of $\mathrm{SjVO}_{2}$ monitoring}

$\mathrm{SjVO}_{2}$ monitoring provides a means of indirectly assessing the brain's ability to extract and metabolize oxygen. Cerebral oxygen delivery $\left(\mathrm{DO}_{2}\right)$ is the product of $\mathrm{CBF}$ and arterial oxygen content. In the healthy individual, the cerebral metabolic rate $\left(\mathrm{CMRO}_{2}\right)$ is coupled to $\mathrm{CBF}$ such that when $\mathrm{CMRO}_{2}$ increases, $\mathrm{CBF}$ increases to match demand. The extraction ratio between arterial and venous blood remains constant. This is not the case in patients with head injury in whom $50 \%$ or more exhibit evidence of defective cerebral autoregulation and subsequent uncoupling of $\mathrm{CBF}$ from $\mathrm{CMRO}_{2} \cdot{ }^{1}$

By the Fick principle cerebral oxygen consumption can be calculated:

$\mathrm{CMRO}_{2}=\mathrm{CBF} \times\left(\right.$ arterial $\mathrm{O}_{2}$ content - jugular venous $\mathrm{O}_{2}$ content);

Where:

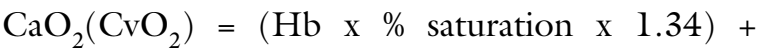
(arterial or venous $\mathrm{O}_{2}$ tension $\mathrm{x} 0.003$ ).

As dissolved oxygen is negligible and can be ignored and since hemoglobin is constant, the content of oxygen is really proportional to the saturation and therefore the difference in arterial-venous (A-v) content of blood can be determined by the difference in $\mathrm{SaO}_{2}$ and $\mathrm{Sj}_{\mathrm{VO}}$.

$\mathrm{SjVO}_{2}$ is therefore a function of the arterial oxygen saturation, $\mathrm{CBF}$ and $\mathrm{CMRO}_{2}$. In the situation where $\mathrm{CMRO}_{2}$ increases without a concomitant increase in $\mathrm{CBF}$, the $\mathrm{A}-\mathrm{vO}_{2}$ difference will rise in conjunction with cerebral oxygen extraction. This leads to a decrease in oxygen content or saturation of the venous effluent from the brain. As long as hemoglobin and arterial saturation remain constant, the $\mathrm{SjVO}_{2}$ is an indicator of cerebral oxygen demand. ${ }^{2}$

\section{$\mathrm{SjVO}_{2}$ catheter}

\section{Catheter insertion}

The internal jugular veins drain virtually all of the blood from the brain. In most individuals the right lateral sinus is the larger of the two. It is unclear as to whether sufficient mixing of venous blood occurs to ensure that the oxygen saturation in the two sinuses is similar. Autopsy specimens have revealed that blood draining the subcortical areas tends to flow into the left lateral sinus while the cortical areas drain via the right. ${ }^{3,4}$ Several small series have examined the relationship between side of catheter insertion and venous oxygen saturation. ${ }^{5,6}$ Most found similar saturations from both internal jugular veins, although it would appear that this might only be true in the case of diffuse cerebral injury. ${ }^{7}$ It is likely however, in patients with focal disease i.e., stroke or unilateral hemorrhage, that there would be a greater difference between the two sinuses. ${ }^{8}$ The question therefore is: given that $\mathrm{Sj}_{\mathrm{VO}}$ is supposed to be representative of the global oxygen consumption by the brain, on which side should the catheter be inserted?

As the flow in the jugular veins is not the same, it would seem logical to insert the catheter into the vein with the greatest flow. There are several methods by which this can be accomplished. The first is purely functional where each jugular vein is compressed in turn and the catheter inserted into the vein with the largest rise in ICP following this manoeuver. ${ }^{2}$ The second uses the admission computer tomography scan to assess the jugular foramina and assumes that the larger must have the greater flow. ${ }^{9}$ The third uses ultrasound to visualize the dominant vein. None of these procedures has been studied in a controlled way and there is no evidence that the side of insertion is associated with better clinical outcome. Some advocate inserting the catheters into the side of injury but this is controversial. ${ }^{9}$

\section{Equipment}

During the early 1900's, the jugular bulb was pierced directly to obtain cerebral venous oxygen saturation. Later, permanent catheters were inserted high in the internal jugular vein. This allowed repetitive sampling of $\mathrm{Sj}_{\mathrm{VO}}$ without repeated needle punctures. More recently, fibreoptic technology has allowed the development of in vivo spectrophotometric catheters. The catheters commonly available in North America include the Oximetrix $3 \circledR$ system from Abbott Laboratories (Illinois, USA) and the Edslab system from Baxter Healthcare ${ }^{\circledR}$ (Irvine, California, USA). ${ }^{10}$ Although the systems are similar, the Oximetrix 3 has the advantage of using three light wavelengths allow- 
ing measurement of both the hemoglobin concentration and oxygen saturation. With the Edslab system, the hemoglobin has to be entered manually. In general, both units appear to have equivalent sensitivity and specificity. Although the Oximetrix 3 can be calibrated prior to insertion, it is recommended that they undergo in vivo calibration at least daily and when the saturation readings are in question.

\section{Catheter placement}

The technique for retrograde cannulation of the internal jugular is relatively simple. The patient is positioned either horizontally or in a slight head down position. Care should be taken not to allow the ICP to increase above $20 \mathrm{mmHg}$. The internal jugular vein is cannulated in the cephalad direction, either distally between the heads of the sternocleidomastoid or more proximally, at the level of the cricoid ring. The Seldinger technique is used and a pediatric introducer with a luer lock adapter is inserted. The fibreoptic catheter is then advanced through the introducer to the jugular bulb, approximately at the level of the mastoid process.

Once the catheter is inserted, it is critical that the correct position be attained in order to limit the contamination from extra cerebral blood. Although, this is thought to represent only $3 \%$ of the blood in the jugular vein, there are anecdotal reports of far greater contamination. ${ }^{11}$ The catheter should sit as close to the roof of the jugular bulb as possible. Even a $2-\mathrm{cm}$ difference can lead to as much as $10 \%$ contamination. This rises exponentially as the tip is withdrawn further. The position of the catheter tip can be confirmed by either a lateral or an antero-posterior (AP) neck radiograph. ${ }^{12} \mathrm{On}$ the lateral film, the catheter tip must be above the disc of $\mathrm{Cl} / \mathrm{C} 2$ and as close to the skull base as possible (Figure 1). On AP view, a correctly placed tip should lie cranial to a line extending from the atlanto-occipital joint space and caudal to the lower margin of the orbit. The catheter tip should also lie cranial to a line connecting the tips of the mastoid processes.

\section{Other modalities for measuring cerebral oxygen requirements}

The accuracy of the $\mathrm{SjOO}_{2}$ monitor has been compared to other modes of intracerebral oxygen monitoring. The possibility of using systemic mixed venous oxygenation as a surrogate of $\mathrm{SjVO}_{2}$ has been studied. ${ }^{8}$ Given that the brain receives $15 \%$ of cardiac output and that the extraction of oxygen is more efficient, it seems illogical to compare $\mathrm{SjVO}_{2}$ to systemic venous saturation. Near-infrared spectroscopy has been used to measure local oxygenation in the brain. ${ }^{13}$ It has several limitations, which include technical difficulties associat-

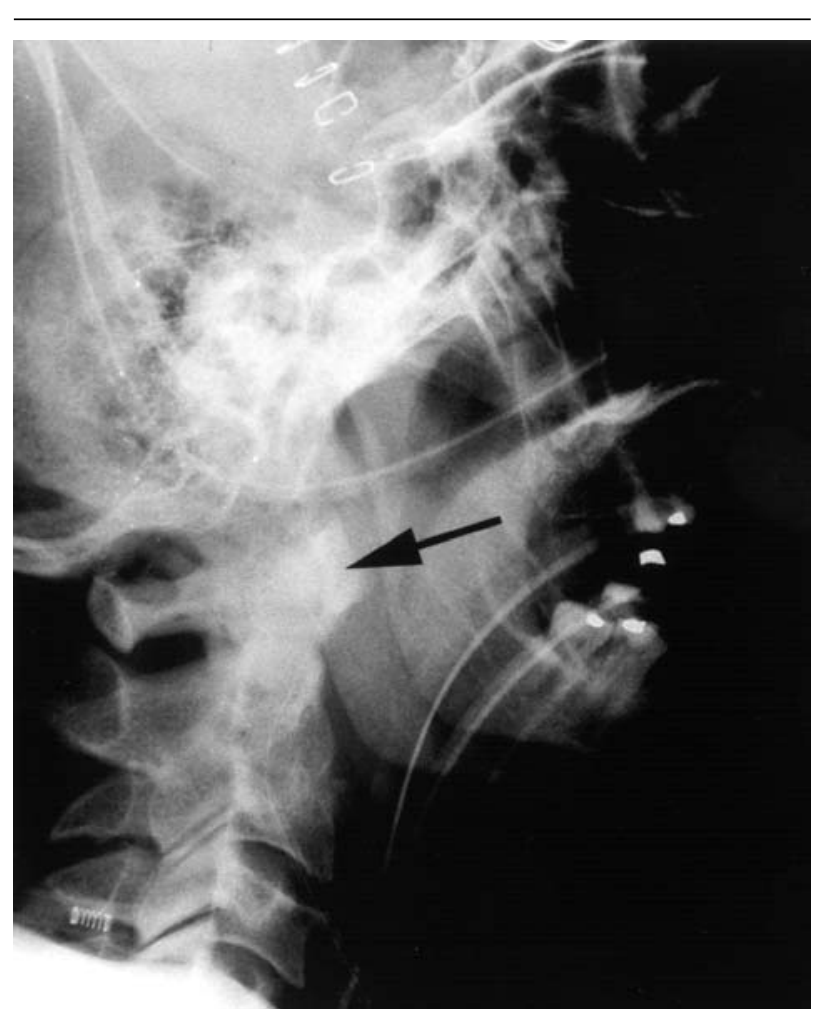

FIGURE I Lateral neck radiograph demonstrating catheter tip position (black arrow).

ed with the optimum path length and distortion by extracellular tissue. A more invasive technique for measuring local oxygen levels is the use of intraparenchymal microcatheters. Although they give an accurate measurement of local conditions, the correlation with global cerebral oxygen levels is less clear. Gopinath compared brain tissue oxygen $\mathrm{PaO}_{2}$ levels with $\mathrm{SjVO}_{2}$ and noted that they provided complementary information and that neither technique alone identifies all episodes of ischemia. ${ }^{14}$ Furthermore, it was clear that tissue $\mathrm{PaO}_{2}$ monitors tend to reflect local rather than global conditions. ${ }^{15}$ It could be argued that, as they measure different areas of the brain, both tissue probes and $\mathrm{SjVO}_{2}$ catheters should be used.

\section{Interpretation}

The monitoring of cerebral venous oxygen saturation is an integral part of multimodality monitoring following acute brain insult. Together with ICP, arterial pressure, transcranial Doppler (TCD) and evoked potentials, $\mathrm{SjVO}_{2}$ can be used to assess the impact of various interventions on cerebral metabolism. ${ }^{16,17}$ Normally, if $\mathrm{DO}_{2}$ decreases, the oxygen extraction 
ratio increases and $\mathrm{SjVO}_{2}$ will decrease acutely. This leads to an increase in CBF resulting in an improved oxygen delivery. When autoregulation is intact, metabolic requirements would be re-established and the oxygen extraction ratio would decrease again. In the setting of brain injury however, autoregulation may be dysfunctional and therefore unable to compensate for the changing oxygen requirements. ${ }^{18}$ If the desaturation is not identified and managed appropriately, permanent brain damage may result. ${ }^{19}$ There is evidence that early insertion of catheters is associated with an improvement in outcome. ${ }^{19}$

\section{Normal values}

Studies in healthy individuals suggest that normal $\mathrm{SjVO}_{2}$ values range somewhere between $55 \%$ and $71 \%{ }^{20,21}$ This is lower than mixed venous oxygen saturation and reflects the increased oxygen requirements of the normal brain. Whether this is true for patients with cerebral injury is not clear. Healthy volunteers are able to tolerate fairly low levels of venous oxygen saturation before neurological deficits become apparent. This is not the case in patients with head injury in who desaturation is associated with a worsened outcome. ${ }^{19,20}$ In fact, a single episode of desaturation below $50 \%$ is associated with a doubling of the mortality rate. ${ }^{21}$ Even in patients undergoing elective cardiovascular surgery, venous oxygen saturations below $50 \%$ are associated with an increase in the incidence of neurological complications. ${ }^{22}$ Current recommendations are to maintain the $\mathrm{SjVO}_{2}$ between $55 \%$ and $75 \%$ to allow for a margin of error.

The accuracy of $\mathrm{SjOO}_{2}$ measurement may be affected by a variety of factors including hemoglobin concentration, systemic arterial oxygen saturation, core temperature and $\mathrm{CO}_{2}$ levels. For this reason, many now use other measures of oxygen utilization to complement $\mathrm{SjVO}_{2}{ }^{2}$ These include the cerebral arterialvenous oxygen saturation difference and lactate-oxygen index. The latter has been used extensively in the study of cerebral metabolism. ${ }^{10}$

\section{Decreasing $\mathrm{SjVO}_{2}$ (Figure 2)}

A decrease in the $\mathrm{SjOO}_{2}$ represents an increase in cerebral oxygen extraction. In acute brain injury, this may result from systemic hypoxia, low $\mathrm{CBF}$ secondary to hypotension or vasospasm or increased ICP with a subsequent decrease in CPP. ${ }^{5,23}$ Factors that increase cerebral oxygen demand such as seizures or pyrexia may also play a role. In the setting of decreased $\mathrm{SjVO}_{2}$, it is necessary to determine which of the above play a role and to treat accordingly. ${ }^{24}$ In a study of over 100 patients admitted to an intensive care unit after trau-

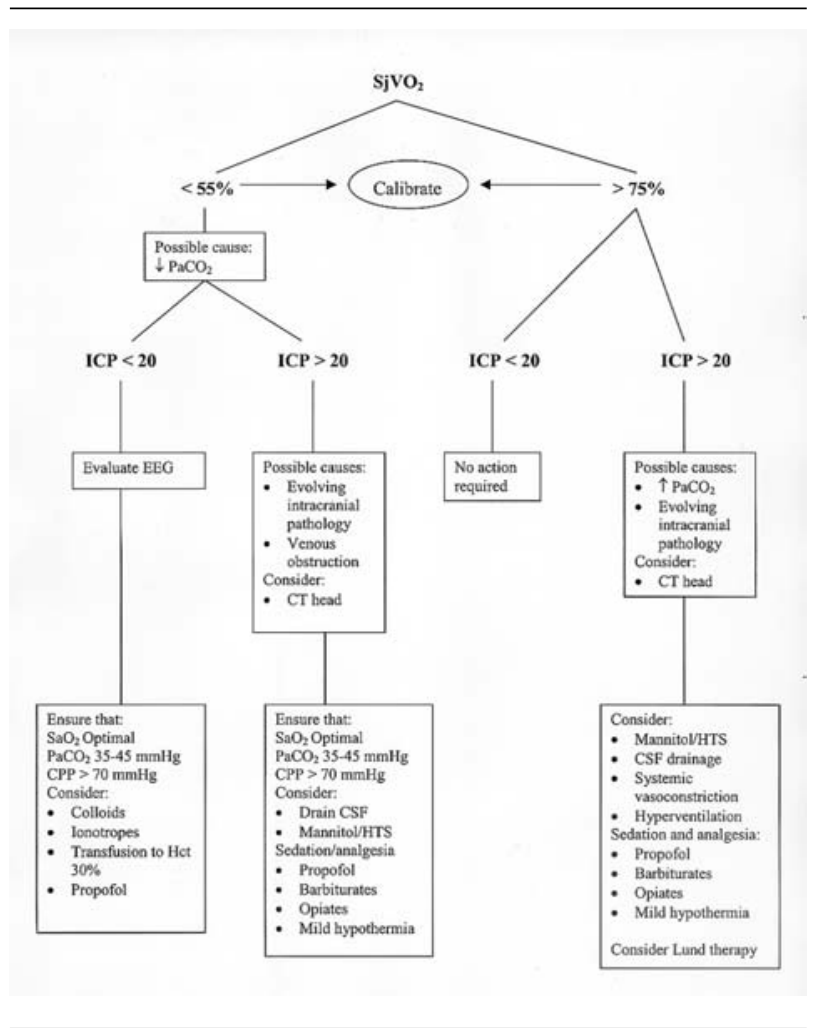

FIGURE 2 Interpretation and management of an abnormal $\mathrm{SjVO}_{2}$. HTS = hypertonic saline.

matic brain injury (TBI), Gopinath et al. demonstrated that multiple episodes of low $\mathrm{SjVO}_{2}$ were associated with poorer outcomes than patients who had only one or no desaturations. ${ }^{20}$

\section{Increasing $\mathrm{SjVO}_{2}$ (Figure 2)}

The interpretation and management of increased $\mathrm{SjVO}_{2}$ can be potentially more challenging. One possibility is that the patient is experiencing abnormally high blood flow to the brain secondary to the loss of autoregulation. A more sinister situation is where the brain tissue is unable to extract oxygen from the blood or where the ICP is so high that blood is effectively shunted past the capillary beds leading to arterial blood in the venous system and focal ischemia. High $\mathrm{SjVO}_{2}$ values have also been associated with poor outcomes. ${ }^{25}$ A recent study by Cormio et al. confirmed this observation and further subdivided outcome based on whether the high $\mathrm{SjVO}_{2}$ was a reflection of hyperemia or a decreased $\mathrm{CMRO}_{2}$ with the latter associated with a worse result. ${ }^{25}$ 


\section{Clinical applications} TBI

Many cases of severe acute brain injury admitted to the neurointensive care unit result from trauma. Early insertion of $\mathrm{SjVO}_{2}$ monitors has been recommended following TBI as the first $12 \mathrm{hr}$ postinjury are often associated with a decrease in cerebral perfusion. ${ }^{19}$ Vigue et al. showed that CPP correlates fairly well with cerebral $\mathrm{SjVO}_{2}$ monitoring and as such, should be optimized to ensure that cerebral metabolic requirements are met. ${ }^{26-28}$ In a study of 150 patients with severe head trauma De Deyne found that 38\% experienced desaturations during the first $12 \mathrm{hr}$. The cause in half the patients was a low mean arterial pressure (MAP) while a low $\mathrm{PaCO}_{2}$ was observed in the remainder. ${ }^{19}$ Several authors have demonstrated an association between cerebral oxygen desaturation and poor neurological outcome. In a recent study of 50 trauma patients, $\mathrm{Sj}_{\mathrm{VO}}$ desaturation was the only factor associated with outcome. ${ }^{27}$ In another study the percentage of patients with a poor neurological outcome was $90 \%$ with multiple episodes of desaturation compared to $55 \%$ in patients with no episodes of desaturation. ${ }^{20}$ Further trials are necessary to confirm the benefit of $\mathrm{SjVO}_{2}$ targeted therapy in the first $24 \mathrm{hr}$ post TBI.

In addition to confirming the deleterious effects of low $\mathrm{CPP}, \mathrm{SjVO}_{2}$ can be used to monitor interventional therapies. The use of mannitol is common in the setting of cerebral edema and raised ICP. ${ }^{28}$ There is some evidence that mannitol may initially reduce cerebral oxygenation. This can be detected by the use of the $\mathrm{SjVO}_{2}$ monitor. Hyperventilation has been used to rapidly decrease ICP in patients with intractable intracranial hypertension. The danger exists that the $\mathrm{PaCO}_{2}$ is decreased to the point where cerebral oxygenation may be compromised. Indeed, the Brain Trauma Foundation recommends maintaining $\mathrm{PaCO}_{2}$ between $30-35 \mathrm{mmHg} .{ }^{29}$ Approximately $20 \%$ of patients with intracranial hypertension have a mismatch of CBF to metabolism where blood flow outstrips cerebral metabolic requirements. Hyperventilation in this group may lower blood flow and improve intracranial hypertension. Cruz investigated this so-called flow-metabolism coupling. In a study of 353 adults with severe acute brain injury, he compared therapies directed at cerebral extraction of oxygen and CPP as compared to management of CPP alone. The study demonstrated a significantly better outcome in the cerebral oxygen extraction group as compared to controls. ${ }^{30} \mathrm{SjVO}_{2}$ monitoring is able to assist in identifying the threshold where further reductions in $\mathrm{PaCO}_{2}$ could lead to cerebral ischemia. ${ }^{31}$

Due to the lack of well-designed controlled trials, treatment management of TBI often depends on the philosophy of individual centres. ${ }^{32}$ The Brain Trauma Foundation Guidelines do not review the use of the $\mathrm{Sj}_{\mathrm{VO}}$ monitor, but there is a suggestion that this technique may be useful in guiding second tier therapy in cases of refractory ICP. ${ }^{29}$ The European Brain Injury Consortium guidelines do not review the $\mathrm{SjVO}_{2}$ moni$\operatorname{tor}^{33}$ and the Italian Society for Anaesthesia, Analgesia, Reanimation and Intensive Care provide suggested criteria for its use. ${ }^{34}$ Despite this lack of consensus, many centres in North America and abroad routinely insert these catheters. ${ }^{5,35}$

\section{Other}

More recently, the use of $\mathrm{SjVO}_{2}$ monitors during cardiac surgery with cardiopulmonary bypass has been explored. ${ }^{36}$ Although the $\mathrm{SjVO}_{2}$ does not change during the initiation phase of normothermic $\mathrm{CPB}$, the potential for marked desaturation is present during the rewarming phase. ${ }^{37}$ Desaturation appears to be associated with low MAP, low hematocrit and rapid rewarming. It is now possible to assess the influence of the various warming and cooling techniques on cerebral oxygenation. ${ }^{38}$ Although the optimum level of $\mathrm{SjVO}_{2}$ in this group is unclear, several studies have indicated that a saturation of less then $50 \%$ is associated with increased mortality and poor neurological outcome. ${ }^{39}$ It should be noted that it has yet to be shown whether the catheters used for continuous monitoring are accurate at low temperatures $\left(<32^{\circ} \mathrm{C}\right) .{ }^{40}$

$\mathrm{SjVO}_{2}$ has been measured after cardiac arrest and an association found between high saturations and death. ${ }^{41}$ Whether this reflects the inability of the neurons to extract oxygen is not known. $\mathrm{SjVO}_{2}$ monitoring following subarachnoid hemorrhage is under investigation. ${ }^{42}$ The use of TCD to diagnose vasospasm has become fairly commonplace. One of the difficulties with the TCD is distinguishing hyperemia from vasospasm. ${ }^{43}$ The management of these two conditions is markedly different. The $\mathrm{SjVO}_{2}$ may be used in this setting, as patients with hyperemia would demonstrate markedly increased venous oxygen saturation while in severe vasospasm, the saturation would be decreased. There is no outcome data for this technique.

\section{Conclusion}

$\mathrm{SjVO}_{2}$ monitoring is only one of many new approaches to cerebral monitoring. Other recently described techniques include cerebral tissue oxygen monitoring, microdialysis and near infra-red spectrophotometry. Whether metabolic monitoring will have an impact on outcome remains to be seen. As discussed, the accuracy of the $\mathrm{SjVO}_{2}$ can be influenced by various technical factors and these need to be addressed before any con- 
sideration is given to altering management. Although we are unable to influence the primary cerebral insult following acute brain injury, much morbidity can potentially be avoided by limiting the secondary brain injury that occurs in the intensive care unit. ${ }^{44}$ As with any monitoring technique the information is only as good as the clinician's ability to interpret it. With more understanding and greater use, $\mathrm{SjVO}_{2}$ monitoring has the potential to complement our current management protocols and possibly improve patient outcomes.

\section{References}

1 Obrist WD, Langfitt TW, Jaggi JL, Cruz J, Gennarelli TA. Cerebral blood flow and metabolism in comatose patients with acute head injury. Relationship to intracranial hypertension. J Neurosurg 1984; 61: 241-53.

2 Feldman Z, Robertson CS. Monitoring of cerebral hemodynamics with jugular bulb catheters. Crit Care Clin 1997; 13: 51-77.

3 Hatiboglu MT, Anil A. Structural variations in the jugular foramen of the human skull. J Anat 1992; 180: 191-6.

4 Lam JMK, Chan MSY, Poon WS. Cerebral venous oxygen saturation monitoring: is dominant jugular bulb cannulation good enough? Br J Neurosurg 1996; 10: 357-64.

5 van den Brink WA, van Santbrink $H$, Avezaat CJJ, et al. Monitoring brain oxygen tension in severe head injury: the Rotterdam experience. Acta Neurochir Suppl 1998; 71: 190-4.

6 Metz C, Holzschuh M, Bein T, Kallenbach B, Taeger K. Jugular bulb monitoring of cerebral oxygen metabolism in severe head injury: accuracy of unilateral measurements. Acta Neurochir Suppl 1998; 71: 324-7.

7 Komiyama M, Kan M, Shigemoto T, Kaji A. Marked regional heterogeneity in venous oxygen saturation in severe head injury studied by superselective intracranial venous sampling: case report. Neurosurgery 1999; 45: 1469-72.

8 Schell RM, Cole DJ. Cerebral monitoring: jugular venous oximetry. Anesth Analg 2000; 90: 559-66.

9 Stocchetti N, Paparella A, Bridelli F, Bacchi M, Piazza $P$, Zuccoli $P$. Cerebral venous oxygen saturation studied with bilateral samples in the internal jugular veins clinical study. Neurosurgery 1994; 34: 38-43.

10 Macmillan CSA, Andrews PJD. Cerebrovenous oxygen saturation monitoring: practical considerations and clinical relevance. Intensive Care Med 2000; 26: 1028-36.

11 Matta BF, Lam AM. The rate of blood withdrawal affects the accuracy of jugular venous bulb. Oxygen saturation measurements. Anesthesiology 1997; 86: 806-8.
12 Bankier AA, Fleischmann D, Windisch A, et al. Position of jugular oxygen saturation catheter in patients with head trauma: assessment by use of plain films. Am J Roentgenol 1995; 16: 437-41.

13 Lewis SB, Myburgh JA, Thornton EL, Reilly PL. Cerebral oxygenation monitoring by near-infrared spectroscopy is not clinically useful in patients with severe closed-head injury. A comparison with jugular venous bulb oximetry. Crit Care Med 1996; 24: 1334-8.

14 Gopinath SP, Valadka AB, Uzura M, Robertson CS. Comparison of jugular venous oxygen saturation and brain tissue $\mathrm{PO}_{2}$ as monitors of cerebral ischemia after head injury. Crit Care Med 1999; 27: 2337-45.

15 Gupta AK, Hutchinson PJ, Al-Rawi P, et al. Measuring brain tissue oxygenation compared with jugular venous oxygen saturation for monitoring cerebral oxygenation after traumatic brain injury. Anesth Analg 1999; 88: 549-53.

16 Bardt TF, Unterberg AW, Kiening KL, Schneider G-H, Lanksch WR. Multimodal cerebral monitoring in comatose head-injured patients. Acta Neurochir (Wien) 1998; 140: 357-65.

17 Unterberg AW, Kiening KL, Hartl R, Bardt T, Sarrafzadeh AS, Lanksch WR. Multimodal monitoring in patients with head injury: evaluation of the effects of treatment on cerebral oxygenation. J Trauma 1997; 42(5S): S32-7.

18 Jünger EC, Newell DW, Grant GA, et al. Cerebral autoregulation following minor head injury. J Neurosurg 1997; 86: 425-32.

19 De Deyne C, Decruyenaere J, Calle P, et al. Analysis of very early jugular bulb oximetry data after severe head injury: implications for the emergency management? Eur J Emerg Med 1996; 3: 69-72.

20 Gopinath SP, Robertson CS, Contant CF, et al. Jugular venous desaturation and outcome after head injury. J Neurol Neurosurg Psychiatry 1994; 57: 717-23.

21 Sheinberg $M$, Kanter MJ, Robertson CS, Contant CF, Narayan RK, Grossman RG. Continuous monitoring of jugular venous oxygen saturation in head-injured patients. J Neurosurg 1992; 76: 212-7.

22 Chen C-S, Leu B-K, Liu K. Detection of cerebral desaturation during cardiopulmonary bypass by cerebral oximetry. Acta Anaesthesiol Sin 1996; 34: 173-8.

23 Dearden NM. Mechanisms and prevention of secondary brain damage during intensive care. Clin Neuropathol 1998; 17: 221-8.

24 Artru F, Jourdan C, Perret-Liaudet A, Charlot M, Mottolese $C$. Low brain tissue oxygen pressure: incidence and corrective therapies. Neurol Res 1998; 20(Suppl 1): S48-51.

25 Cormio $M$, Valadka $A B$, Robertson $C S$. Elevated jugular venous oxygen saturation after severe head injury. J 
Neurosurg 1999; 90: 9-15.

26 Vigué B, Ract C, Benayed $M$, et al. Early $\mathrm{SjvO}_{2}$ monitoring in patients with severe brain trauma. Intensive Care Med 1999; 25: 445-51.

27 Fandino J, Stocker R, Prokop S, Trentz O, Imbof $H-G$. Cerebral oxygenation and systemic trauma related factors determining neurological outcome after brain injury. J Clin Neurosci 2000; 7: 226-33.

28 Schneider G-H, von Helden A, Lanksch WR, Unterberg $A$. Continuous monitoring of jugular bulb oxygen saturation in comatose patients - therapeutic implications. Acta Neurochir (Wien) 1995; 134: 71-5.

29 The Brain Trauma Foundation. The American Association of Neurological Surgeons. The Joint Section on Neurotrauma and Critical Care. Management and Prognosis of Severe Traumatic Brain Injury: Part 1: Guidelines for the management of severe traumatic brain injury. J Neurotrauma 2000; 17(6/7): 449-554.

$30 \mathrm{Cruz} \mathrm{J}$. The first decade of continuous monitoring of jugular bulb oxyhemoglobinsaturation: management strategies and clinical outcome. Crit Care Med 1998; 26: $344-51$.

31 Schaffranietz L, Heinke $W$. The effect of different ventilation regimes on jugular venous oxygen saturation in elective neurosurgical patients. Neurol Res 1998; 20(Suppl 1): S66-70.

32 Basso A, Previgliano I, Duarte JM, Ferrari N. Advances in management of neurosurgical trauma in different continents. World J Surg 2001; 25: 1174-8.

33 Maas AIR, Dearden M, Teasdale GM, et al., on behalf of the European Brain Injury Consortium. EBIC- guidelines for management of severe head injury in adults.. Acta Neurochir (Wien) 1997; 139: 286-94.

34 Procaccio F, Stocchetti N, Citerio G, et al. Guidelines for the treatment of adults with severe head trauma (part I). Initial assessment; evaluation and pre-hospital treatment; current criteria for hospital admission; systemic and cerebral monitoring. J Neurosurg Sci 2000; 44: 1-10.

35 Kay A, Teasdale G. Head injury in the United Kingdom. World J Surg 2001; 25: 1210-20.

36 Anastasion E, Geroliolion K, Karakoulas K, Peftoulidon $M$, Giala M. Reliability of continuous jugular venous bulb hemoglobin oxygen saturation during cardiac surgery. J Cardiothorac Vasc Anesth 1999; 13: 276-9.

37 Souter MJ, Andrews PJD, Alston RP. Jugular venous desaturation following cardiac surgery. Br J Anaesth 1998; 81: 239-41.

38 Mutch WAC, Warrian RK, Eschun GM, et al. Biologically variable pulsation improves jugular venous oxygen saturation during rewarming. Ann Thorac Surg 2000; 69: 491-7.

39 Croughwell ND, Newman MF, Blumenthal JA, et al. Jugular bulb saturation and cognitive dysfunction after cardiopulmonary bypass. Ann Thorac Surg 1994; 58: 1702-8.

40 Trubiano P, Heyer EJ, Adams DC, et al. Jugular venous bulb oxyhemoglobin saturation during cardiac surgery: accuracy and reliability using a continuous monitor. Anesth Analg 1996; 82: 964-8.

41 Bunnk G, van der Hoeven JG, Meinders AE. Prognostic significance of the difference between mixed venous and jugular bulb oxygen saturation in comatose patients resuscitated from a cardiac arrest. Resuscitation 1999; 41: 257-62.

42 Citerio G, Cormio M, Portella G, Vascotto E, Galli D, Gaini SM. Jugular saturation $\left(\mathrm{SjvO}_{2}\right)$ monitoring in subarachnoid hemorrhage (SAH). Acta Neurochir Suppl 1998; 71: 316-9.

43 Manno EM. Transcranial Doppler ultrasonography in the neurocritical care unit. Crit Care Clin 1997; 13: 79-104.

44 Jones PA, Andrews PJD, Midgley S, et al. Measuring the burden of secondary insults in head-injured patients during intensive care. J Neurosurg Anesthesiol 1994; 6: 4-14. 